\title{
Oil accumulation kinetic along ripening in four olive cultivars varying for fruit size
}

Catherine BRETON ${ }^{1}$

Irénée SOUYRIS ${ }^{2}$

Pierre VILLEMUR ${ }^{2}$

André BERVILLE ${ }^{2}$

${ }^{1}$ Institut de botanique,

Université Montpellier 2,

Laboratoire de paléoenvironnement, anthracologie, et action de l'homme.

ESA 5059 CNRS, 163 Avenue A Broussonnet,

34165 Montpellier cedex, France

2 INRA, UMR 1097-DIAPC, Bât 33,

2 place Viala F-34060 Montpellier cedex 1

$<$ berville@supagro.inra.fr>

\begin{abstract}
To determine whether oil accumulation pattern is parallel to drupe olive (Olea europaea L) growth and if common climatic parameters may influence oil content we conducted an experiment in rainfed orchards with four olive cultivars, Amygdalolia, Arbequina, Lucques, and Oliviere, differing by fruit size at maturity. Fruits were harvested weekly from July to November. They were counted and weighted before being crushed. Fat content was determined on dry matter using a Minispec RMN. Common climatic parameters were recorded. Variance analyses showed stage effects highly significant. Results showed three different patterns for fruit growth. Dry matter accumulated broadly similarly and the weekly rates were positively correlated with fruit size. Oil accumulation is mostly independent of climatic variation and probably depends on genetic programmes for each cultivar. We defined the main steps and events for olive fruit ripening according to recent knowledge on fruit development.
\end{abstract}

Key words: olive, drupe ripening, environmental effect, oil accumulation, Olea europaea, temporal regulation

\section{Introduction}

Oil accumulation in storage organs follows different patterns depending on the organ kinetic development. For most seed oil such as from Arabidopsis, the kinetic is fast [1] as starting ten days after pollination for sunflower and oil accumulate for about 15 days [1, 2] sustained by gene expression studies involved in desaturation pathways. For the olive, the kinetic is much slow as judged by the expression pattern of the stearoyl-ACP desaturase in the seed and the pulp up to 154 and 196 DAFB, respectively [3]. In the olive drupe, for north Mediterranean full bloom occurred by the second week of May and oil accumulation starts by the beginning of July (5 to 7 weeks after full bloom) and ends by October 22 to 25 . The final ripening stage corresponds to water $(\mathrm{WaC})$ and fresh weight (FW) losses for fruits and this increases the final mill oil yield. In fruit oil such as for the olive, oil accumulates both in the seed and in the pulp (fruit oil), but the pathways are disconnected. They may have different composition [4, 5] for fatty acids. All the drupe part of fruits from one tree has the same genetic composition whereas the seeds have each another genetic composition resulting from the mother tree allele segregation for the female gamete and the alleles from the fertilizing pollen grain. The ratio oil from seed on oil from the pulp is weak and oil composition is considered as being due to pulp.

Several works reported oil accumulation during olive ripening phases for cultivars from Spain, Portugal, Greek and Italy [6-9]. However, these kinds of works deal usually to study fruit changes either for ultrastructure [10], enzyme expression studies such as lipoxygenases [9] or oleosines [8], and compounds accumulation such as phenols [6], triterpenoids [11] and crop load [12]. The common agronomic parameter that varied in most experiments is watering. Both oil and phenol accumulation has been followed with different irrigation strategies [13]. Usually these experiments have been conducted with one cultivar and thus can be extended to others only prudently. The regular interval between two sampling was usually two weeks. Most studies deal with the end of oil accumulation, i.e., October to December. Moreover, in any cases, the main climatic variables (temperature, rainfall and sunniness) have not been recorded. A surveyed on biochemistry of lipid metabolism and stressed environmental factors that may influence fruit oil synthesis stated that differences between the fruits of one tree for oil content are due to environmental factors [14]. Consequently, they recorded light, temperature, water stress, and soil and atmospheric constituents plus damages due to pest attacks as main causes. However, this study did not establish the temporal expression of the enzymes.

Because we plan to study genes involved in olive oil accumulation we followed oil accumulation every week from July to October for four olive cultivars. Due to final oil content higher in cultivars with small fruits than in those with big fruits, we chose cultivars with small (Arbequina), medium (Lucques, Olivière) or big fruits (Amygdalolia). They also differ for olive uses. Trees were in different rainfed orchards and we recorded the main climatic parameters in every place. The main 
results were that olive size increases from July to October according to different patterns at early or late stages. In contrast dry matter accumulation rate increases between July to October but it depends on rains and decreases rapidly with less sunniness. Oil accumulation rate is more regular than the other parameters. All these facts enable us to propose a scheme for oil accumulation to better target important stages to pick up genes of interest in oil accumulation.

\section{Material and methods}

During the summer 2007, two cultivar trees were chosen in rainfed orchard (664 mm/year mean annual rainfall) named Chateau d'Ô managed by the Conseil Général de l'Hérault at Montpellier. Amygdalolia from Greece displayed the biggest fruits and is used both for oil and for table. Olivière from France (Languedoc) displayed medium size fruits, is very productive but has relatively low oil content that leads to also mix uses. Arbequina, from Spain (Catalonia) was in the Supagro rainfed orchard at Montpellier it displayed the smallest fruits and is known for its high oil yield. Lucques from France (Languedoc) is in the Mauguio rainfed orchard $(12 \mathrm{~km})$ from Montpellier close to the sea, it displays medium size fruits and is known as used for table, but it also produces fine oil.

Our experiments suffer of drawbacks inherent to this species. We cannot grow olive trees in an experimental design as for other crops with repeated plots. This explains the choice of cultivars in different orchards. Moreover, because we plan to harvest every week $150 \mathrm{~g}$ of fruits we were prudent to not compromise the last stages of harvest. We wait for mid-July to harvest a reasonable number of fruits at each stage. Probably two earlier stages would be necessary, but it would be at the detriment of the later stages. These difficulties probably explain the absence of equivalent experiments and the scarcity of data at early stages of development in literature. The trees were about fifty year-old, their height, was $4 \mathrm{~m}$ and the total quantity of fruits harvested on each tree was weak enough, compared to the total quantity produced on each tree, for not affecting the spreading out of the remaining fruits.

Full blooming has occurred by May the $7-14^{\text {th }}$ without significant differences between the four cultivars. Thus we choose the $12^{\text {th }}$ as reference day. Pollination occurred by the surrounding olive trees. The fruits were harvested starting July the $12^{\text {th }}$ (61 days after full bloom) and we go on onto November the $16^{\text {th }}$, every week. No fruit choice was performed at each sampling stage. The fruits were then counted and weighted to average one drupe unit. About $120 \mathrm{~g}$ of fruits were harvested each week and crushed in a Waring blender (Waring Blendor) with 4 pulses of $15 \mathrm{~s}$ to homogenize pulp and stones (pits). About 3 times $35 \mathrm{~g}$ of the homogenate were exactly weighted and distributed into three Petri dishes for desiccation at $60{ }^{\circ} \mathrm{C}$ for $72 \mathrm{~h}$. Stabilisation of the dry matter weight (DM) occurred after $48 \mathrm{~h}$. After determination of the DM (3 repeats) the powder was transferred to 3 plastic tubes that were stored frozen at $-30^{\circ} \mathrm{C}$.

For the three repeats an exact weight around $8 \mathrm{~g}$ of the powder was introduced into the cell of a MINISPEC (NMR proton) to record oil

\begin{tabular}{ll} 
& \multicolumn{1}{c}{ Abbreviations } \\
AOC & absolute oil content \\
DAFB & day after full blooming \\
DM & dry matter \\
FW & fresh weight \\
NMR & nucleic magnetic resonance \\
OC & oil content \\
WaC & water content
\end{tabular}

content. Thus all oil content is the mean of 3 separate samples. Calibration curves were obtained from reference samples from $0 \%$ to $50 \%$ oil content from canola and sunflower seeds. Minispec provides absolute oil accumulation values probably correlated with the mill yield.

Climatic data were recorded in the INRA meteorology station in Mauguio and in the Association Bioclimatologique de l'Hérault in Fabrègues (near Montpellier). Daily recorded were averaged by week before computation. Data treatments for statistical computation were used using SAS software (SAS 2002). We followed the parameters: 1) dry matter accumulation (DM \%), water content (WaC \%), drupe weight (DW g), and absolute oil content (AOC \% dry matter). To erase the effect of water accumulation, we computed the average weekly rate of dry matter accumulation and water accumulation per fruit. Beside we compared the data to mean, minimal and maximal temperature $\left({ }^{\circ} \mathrm{C}\right)$, rainfall per day $(\mathrm{mm})$, wind strength $(\mathrm{m} / \mathrm{s})$, evapotranspiration $(\mathrm{mm} /$ day), and sunniness $\left(\mathrm{J} / \mathrm{cm}^{2}\right)$.

\section{Results}

Variance analyses were performed for all and each cultivar to determine whether differences were highly significant between cultivars and at each stage for one cultivar (not shown). We observed an increase of dry matter content (DM) in fruits from July to October (figure 1A). Arbequina displays more DM than the other cultivars. The fruit water content (WaC) correlatively decreased from 70 to $35-40 \%$ (figure 1B). The behaviour of the 4 cultivars is similar except that Arbequina displays less FW and is earlier than the three others (table 1). Arbequina starts earlier oil accumulation. We observed pit sclerification by Augusts 9 to $16^{\text {th }}$ for all cultivars. For the evolution of fruit weight (FW) the differences are important and three types of profiles display specific dynamics (figure 1C). Amygdalolia fruits swell rapidly whereas Arbequina fruits did not swell and FW reached the maximum weight by October. For Lucques and Olivière FW were intermediate. At the late period the fruits from the four cultivars get bigger. After a plateau the FW decreased due to water loss and at 181 DAP they swell again after deep rain $(74 \mathrm{~mm})$ for the four cultivars. Fat content evolves in parallel except for Olivière known for its lower oil content (figure 1D). The overestimation of oil due to water still remaining in tissue although two days for dehydration was estimated to be $6 \%$ based on current measerements on sunflower seed. Oil displayed much more regular rates of accumulation than other parameters.

Weekly rates of dry matter accumulation, water content, and fat accumulation are similar in shape for the four cultivars (figures $1 E, G, H$ ). Fresh weight rate is slightly different for Amygdalolia (figure 1F). WaC weekly rates overwhelmed other variations that control weekly rates of dry matter accumulation and weekly rates of fruits. Consequently, we computed $\mathrm{WaC}$ weekly rates on one hand and, on the other hand, weekly rates of dry matter accumulation (DMA) by fruit (mean weight by fruit) that is not depending on water content (figures 4-5). We observed that the former varied apparently erratically, whereas, DMA varied lineally for all varieties. Obviously, the speed of DMA was related to fruit size.

\section{Comparison with climatic data}

The evolution of climatic data at Mauguio and Fabrègues were plotted for mean temperature, Tmax, Tmin, rainfall/week, evapotranspiration, wind strength, and sunniness (figures $2 A, B$ ).

At Mauguio, which is close to sea, for Lucques climatic data showed that most have no effect except rainfall that increased oil content. The three 


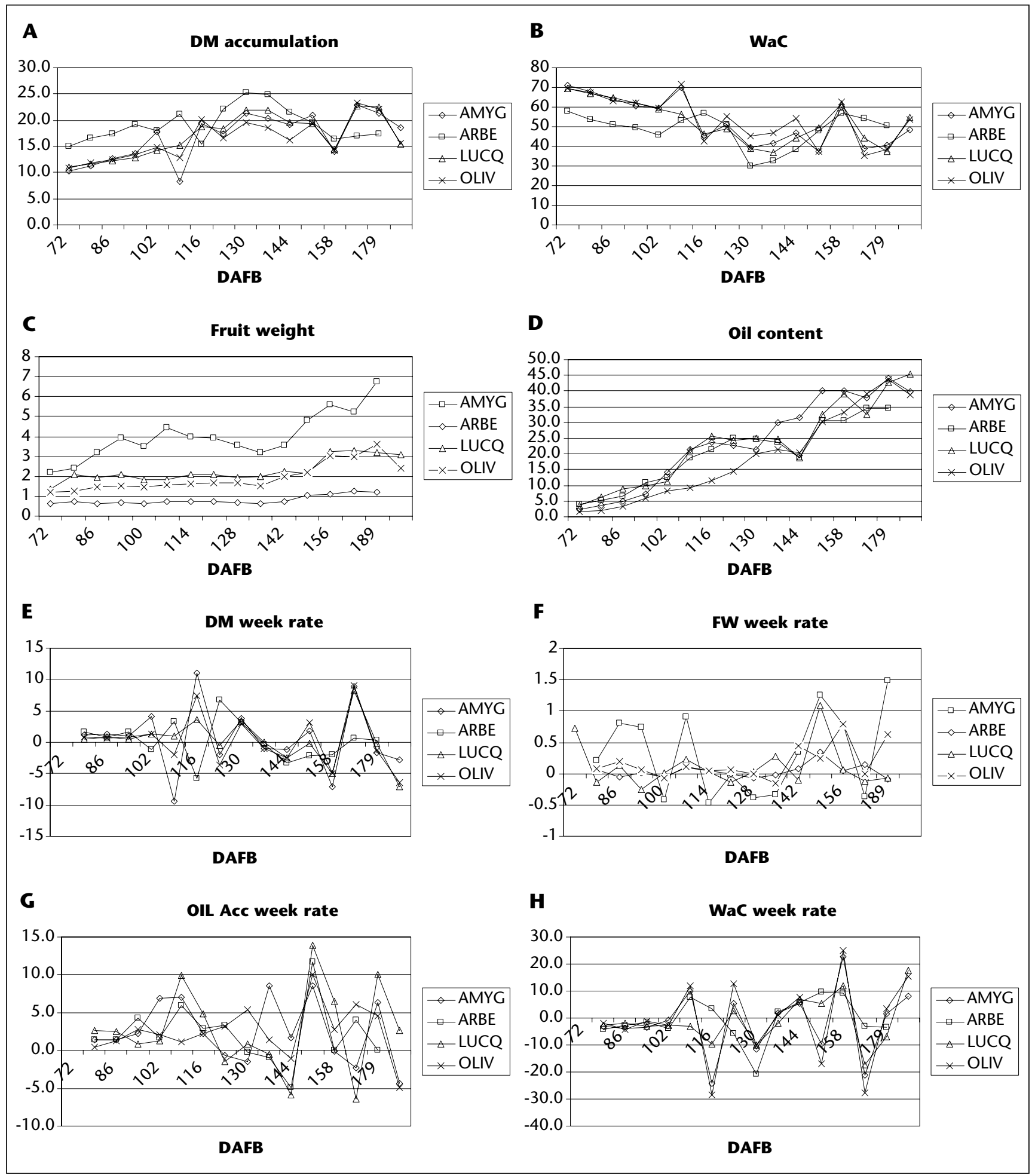

Figure 1. Changes in fruit parameters recorded from July to November with days after full bloom as references. A) Dry matter (DM \%) changes; B) water content (WaC\%) changes; C) fruit weight (FW.g) changes; D) fat content (OC \%of DM) changes; and weekly-rate changes for E) dry matter; F) fruit weight; $G$ ) water content; and H) fat accumulation.

whiles of rain are followed each by an increase of oil content depending on the quantities. For Lucques the DM and WaC curves pointed decreases that are probably due to climatic event as for oil content (figure 2C). Clouds and shadow occurred for 3 days since sunniness drops from
$2500 \mathrm{~J} / \mathrm{cm}^{2}$ an August $14^{\text {th }}$, to 1200 on August the $15^{\text {th }}$ and $1680 \mathrm{~J} / \mathrm{cm}^{2}$ on the 16th. Sunniness decrease fitted the slowdown of dry matter accumulation. In fact the deep rainfall by 151-165 DAF restored the initial rate for oil content on the slope (figure 1E). 
Table 1. Comparison of parameters from 100 fruits sampled with reference experiments on $1 \mathrm{~kg}$ according to [16].

\begin{tabular}{|lllll|}
\hline & \multicolumn{2}{l}{ Mean fresh weight of one fruit } & Lucques & Olivière \\
\cline { 2 - 5 } & Amygdalolia & Arbequina & $3,87 \mathrm{~g}^{\mathrm{a}}$ & $2,63 \mathrm{~g}^{\mathrm{a}}$ \\
\hline Computed on one $\mathrm{kg}[16]$ & $6.57 \mathrm{~g}^{\mathrm{a}}$ & $1,83 \mathrm{~g}^{\mathrm{a}}$ & $1,95 \mathrm{~g}^{\mathrm{b}}$ & $1,48 \mathrm{~g}^{\mathrm{b}}$ \\
& $3.58 \mathrm{~g}^{\mathrm{b}}$ & $1,09 \mathrm{~g}^{\mathrm{b}}$ & $5,70 \mathrm{~g}^{\mathrm{c}}$ & $5,18 \mathrm{~g}^{\mathrm{c}}$ \\
Computed on 100 fruits & $10.49 \mathrm{~g}^{\mathrm{c}}$ & $2,37 \mathrm{~g}^{\mathrm{c}}$ & $3.18 \pm 0.3 \mathrm{~g}$ & $3.27 \pm 0.3 \mathrm{~g}$ \\
\hline
\end{tabular}

${ }^{a}$ Mean fresh weight, ${ }^{b}$ minimal value, ${ }^{c}$ maximal value

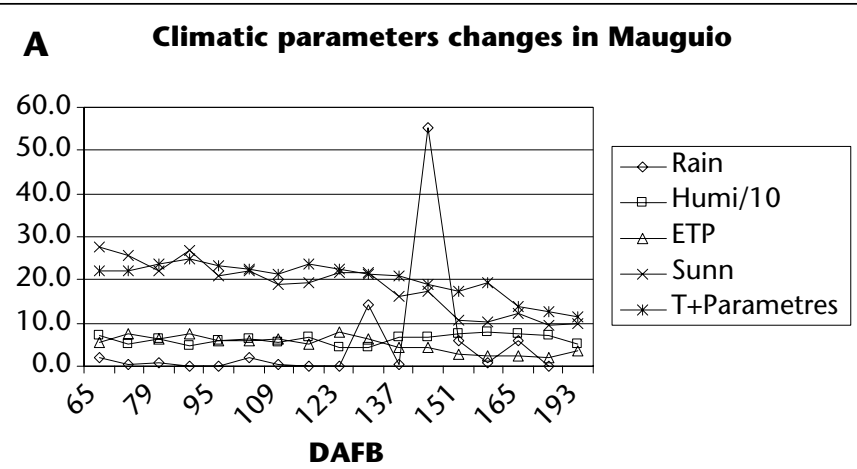

B Climatic parameters in Fabrègues

C

FW week rate

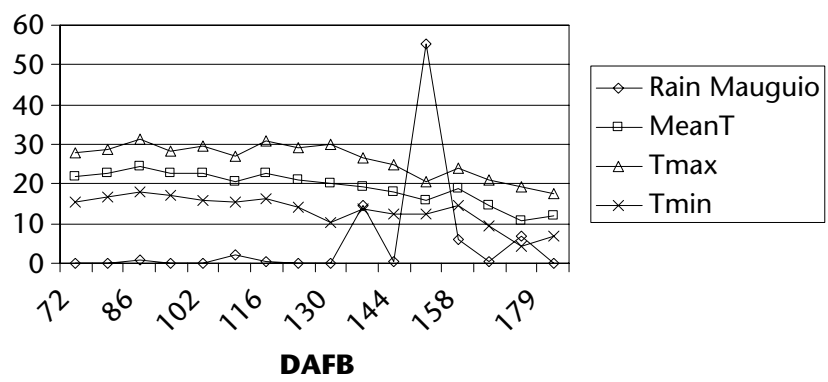

D OIL Accum Rain Fabrègues

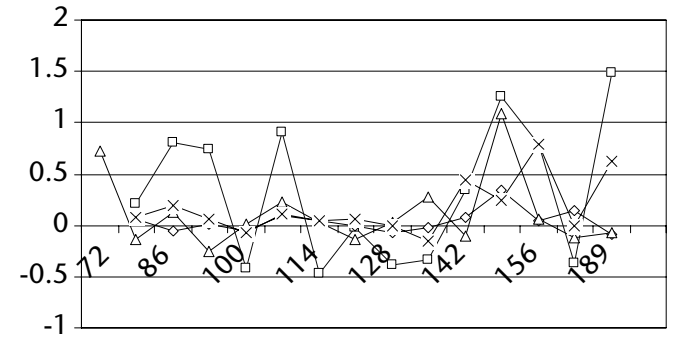

DAFB
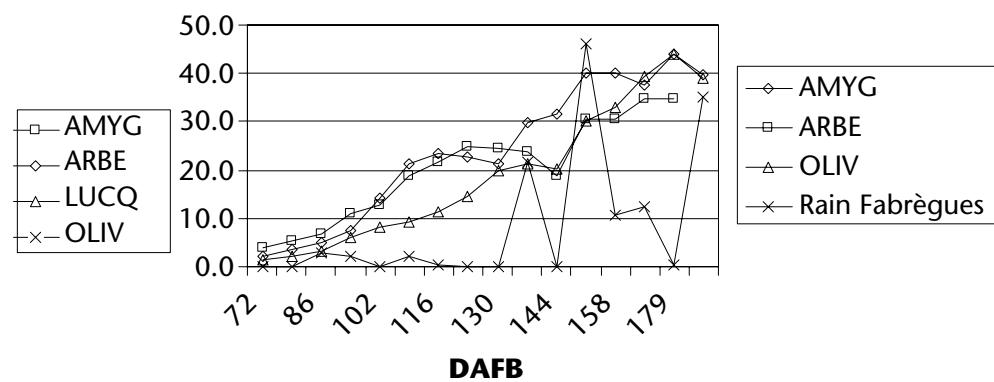

\section{E Oil Accum Rain Mauguio}

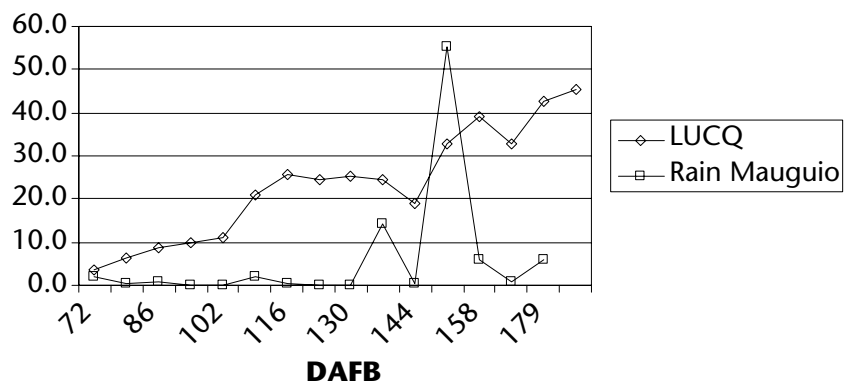

Figure 2. A) Changes in climatic parameters from July to November at Mauguio; B) Changes in climatic parameters from July to November at Fabrègues. C) Comparison of fat content (FC) to rainfalls for Amygdalolia (AMYG), Arbequina (ARBE), Olivière (OLIV) at Fabrègues, and D) Lucques (LUCQ) at Mauguio. E) Comparison of fruit weights to evapotranspiration $(E T P) ; F)$ comparison to fat content $(F C)$ to rainfall changes.

At Fabrègues, inland, the data are not significantly different from those of Mauguio (figures $2 A, B$ ). Arbequina, in the Supagro orchard undergone a drought stress and the rainfall by day from 145 to 166 restored the oil content to the initial slope (figure 2D). Amygdalolia, and Olivière undergone less drought stress and similarly rainfall restored the initial slopes (figures $2 \mathrm{C}, \mathrm{D}$ ). At the end of the process turgid changes occurred and fruit weight decreased due to water losses as well as oil content increases without new fat synthesis. We also noticed changes in fruit 


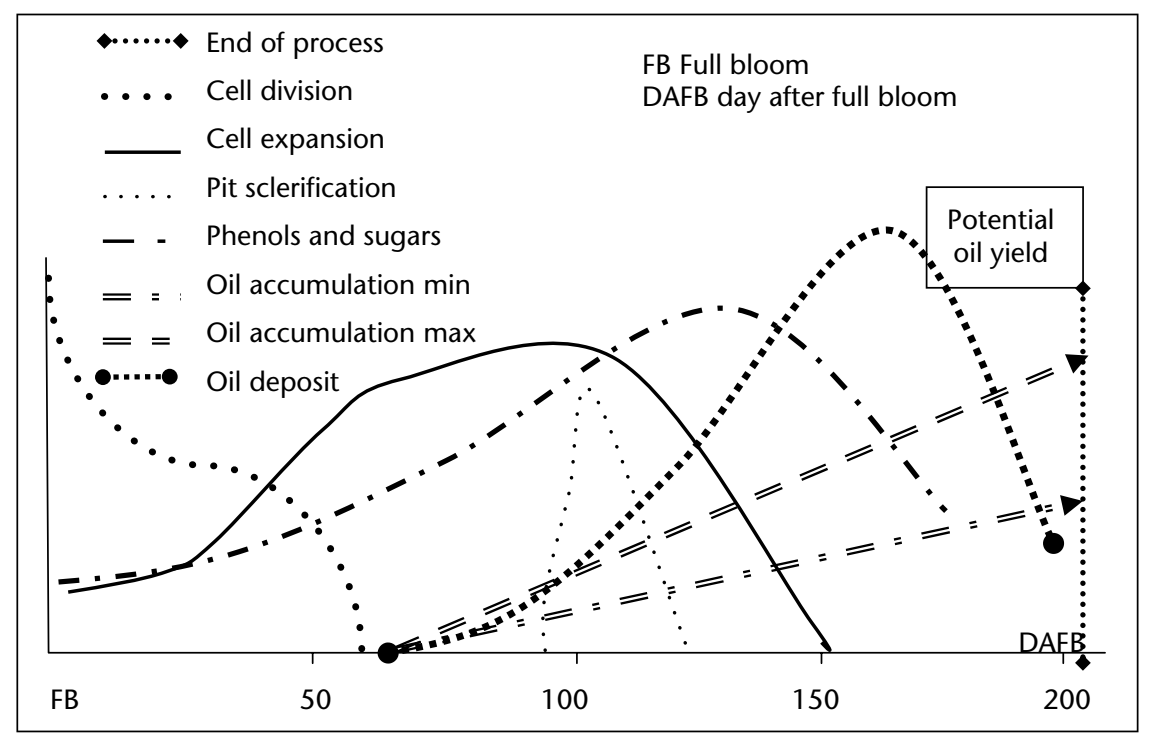

Figure 3. Major developmental changes in the olive fruit during development and ripening. Relative changes in cell division, cell expansion, pit sclerification, phenols and sugars accumulation, and potential oil yield. Oil accumulation lines are shown for two cultivars differing by minimal and higher oil content.

colour for Arbequina by day 145 when half of fruits turning coloured, whereas for the three other cultivars fruits turned progressively black by day 155 for Lucques and 160 for Olivière and Amygdalolia.

ETP measures were equivalent in Mauguio and Fabrègues. We noticed the inverse correlation between ETP lowering and fruit size increasing (figure 2E).

\section{Discussion}

The parameters determined in the four cultivars as well as fruit weight evolution, and dry matter fitted the confident intervals given [15] in different environments for fruits of the four cultivars. In this respect, our experiments were probably significant. The oil mill yields for these cultivars have been recorded but Minispec measurements are above due a systematic error for residual water content (table 2) and absence of oil extraction [15]. The comparison between the four cultivars was considered therefore as meaningful.
Among climatic parameters we checked which could explain most of the variation observed for fruit parameters. Surprisingly, the average temperature as well as the minimal and maximal day value was not correlated with any traits. Sunniness and rainfall have effects. Rainfall restored oil content after drought interval. Drop in dry matter is correlated with sunniness decreases (Not shown). Dry matter content leads probably to protein synthesis, sugar accumulation, and is therefore a prerequisite for further oil accumulation as already shown [16]. Moreover, the same authors have noticed that cultivars with low oil yield at maturity have accumulated much sugar than those with high oil yield. Correlation between decreases in sugars and water and increases in oil content has been confirmed [17].

The comparison of four cultivars with different fruit sizes and weights showed that oil accumulation is independent of fruit weight and is broadly linear. Drought stresses trend to lower the slope and rainfall restores the slope but does not increase yield above the initial slope. Although no climatic parameters disturbed the fruit parameters, all culti-

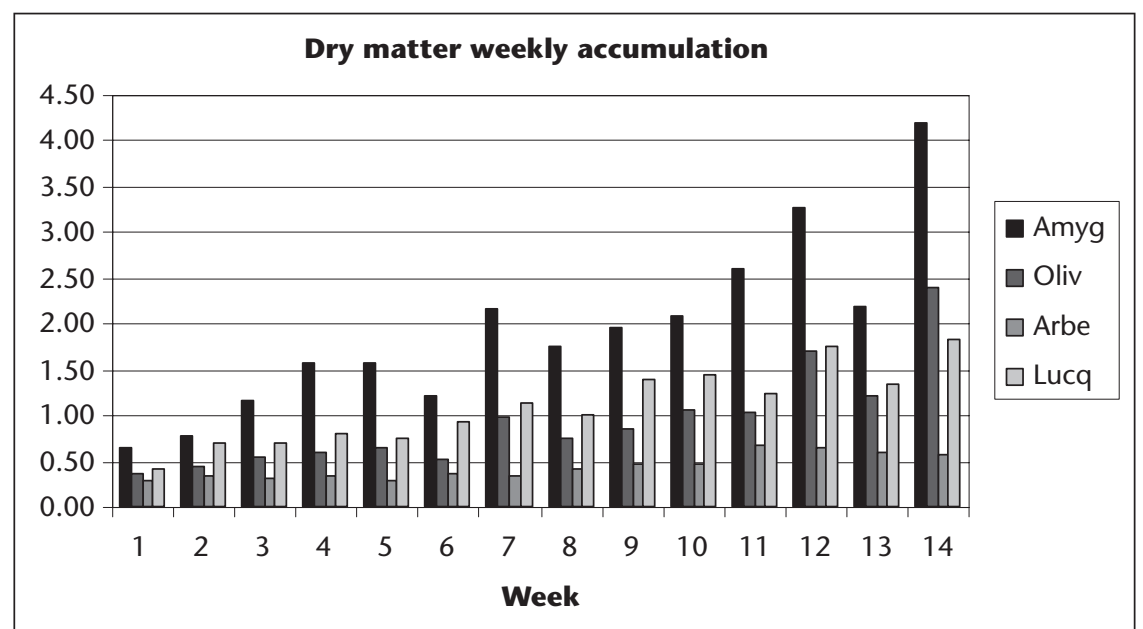

Figure 4. Dry matter weekly accumulation rate between 61 (week 1) to 189 (week 14) DAFB in the four cultivars Amyg (Amygdalolia), Oliv (Olivière), Arbe (Arbequina) and Lucq (Lucques). 


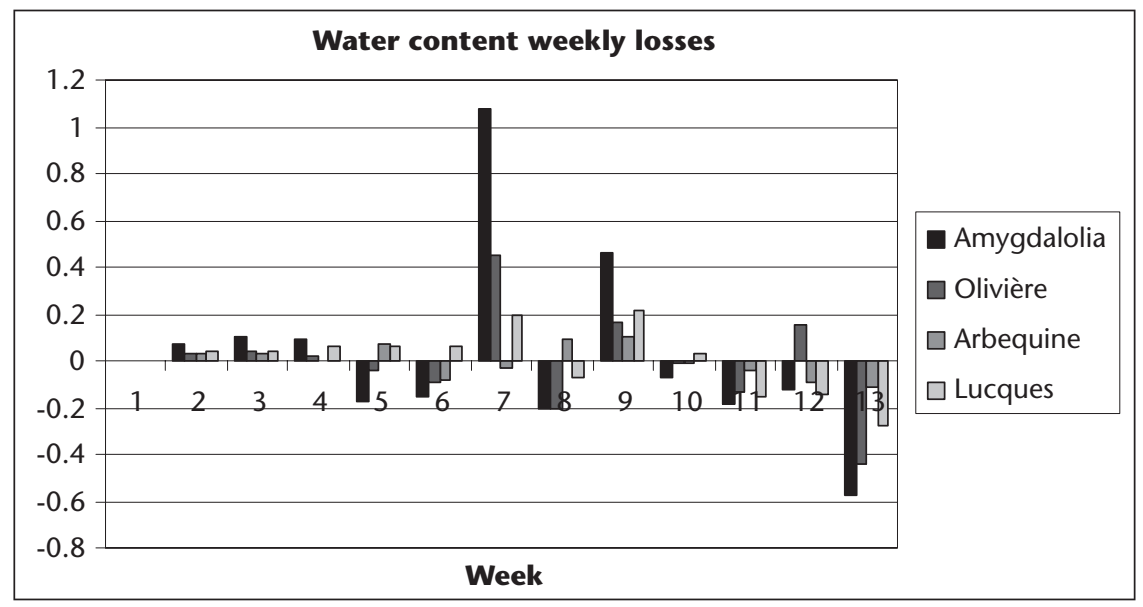

Figure 5. Water content weekly loss rate between 61 (week 1) to 189 (week 14) DAFB in the four cultivars Amygdalolia), Olivière), Arbequina) and Lucques.

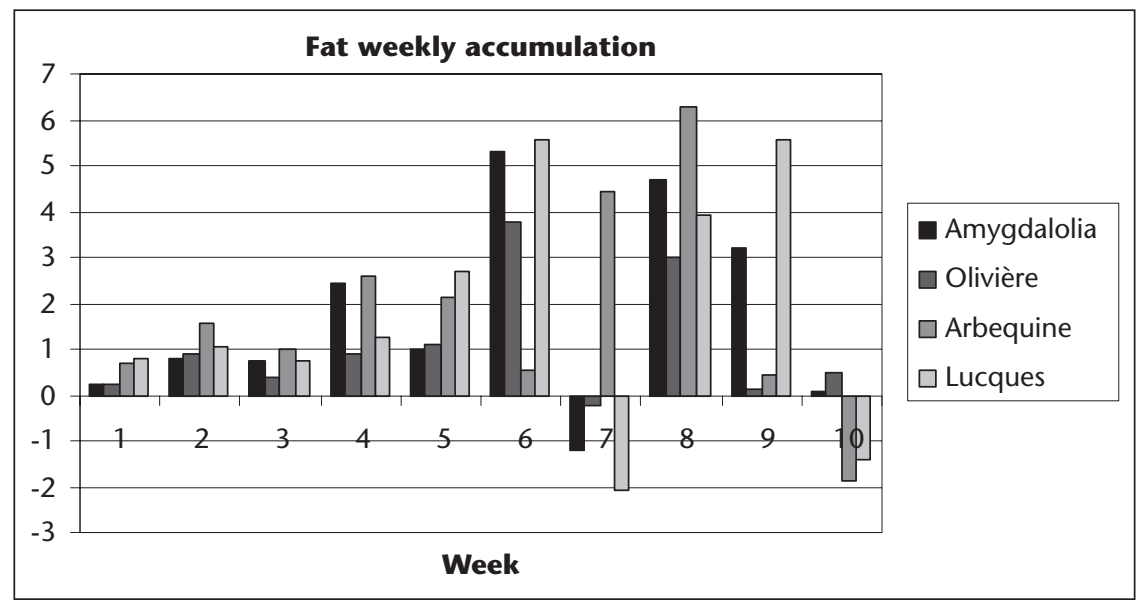

Figure 6. Fat weekly accumulation rate between 61 (week 1) to 189 (week 14) DAFB in the four cultivars Amyg dalolia, Olivière, Arbequina and Lucques.

Table 2. Oil content determined with the Minispec (NMR) for four olive cultivars.

\begin{tabular}{|lllll|}
\hline & Arbequina & Amygdalolia & Lucques & Olivière \\
\hline Oil \%/100 kg fruits [16] & $19.0 \%^{\mathrm{a}}$ & $14,3 \%^{\mathrm{a}}$ & $16 \%^{\mathrm{a}}$ & $15.3 \%^{\mathrm{a}}$ \\
& $13.9 \%^{\mathrm{b}}$ & $8,7 \%^{\mathrm{b}}$ & $14.7 \%^{\mathrm{b}}$ & $12.3 \%^{\mathrm{b}}$ \\
Minispec on 8 g Dry Matter & $27.4 \%^{\mathrm{c}}$ & $19,7 \%^{\mathrm{c}}$ & $23 \%^{\mathrm{c}}$ & $21.4 \%^{\mathrm{c}}$ \\
& $40 \%$ & $36 \%$ & $45.4 \%$ & $40 \%$ \\
\hline
\end{tabular}

${ }^{\mathrm{a}}$ Mean oil yield, ' lower and ${ }^{\mathrm{c} H i g h e r}$ yield measured

vars displays rapid changes from 102 to 130 DAP for DM, FW, and WaC. Probably, these changes are due to sclerification of the pit that consumes DM. Several authors have shown that watering increased oil yield in comparison to controls. As rainfall watering probably restores the initial rate for oil accumulation [13].

Our data suggest that oil accumulation is programmed in the fruit and relatively independent of the environmental conditions. According to findings in other plant fruits, we can transfer the developmental changes followed during tomato to olive $[18,19]$. Arbequina fruit weight evolution in comparison to those of Amygdalolia sustains that cell division stops by the beginning of July by extrapolation of the curves (figure $1 B C)$. Consequently, all further changes in other cultivars are due to cell expansion but the role of regulatory networks for fleshy fruits is much less known than for dry seeds [19].

Thus we propose a scheme to gather all data (figure 3). Olive fruits also undergo marked changes in texture during ripening (due to complex sugars), in colour due to anthocyanin (green, white, reddish, and violet) and in flavour due to phenolic compounds and to alcohols, organic acids and aldehydes (www. britanniafood.com). As already quoted several authors recorded accurately the accumulation of sugars and phenols and polyphenols. However, for the olive the stone plays probably an important role to explain differences since the ratio pulp/stone may vary from 3 for small fruits to 10 for big fruits. Arbequina accumulated apparently oil earlier probably due to earlier oil accumulation in the seed 
than in the pulp [3]. The stone is made of sclerified tissue from the mother plant (outer layer = endocarpe) and the seed (inner part). The seed itself represents weak dry matter but its oil content is by $60 \%$ [4]. Cell expansion is monitored by transcription factors belonging to auxin response factors (ARF) genes. Thus cultivars should differ for these factors. These factors also control the turgid state in Arabidopsis and their diversity should explain differences between fruit weight evolution. Cell expansion is probably sensible to environmental factors such as water stresses.

The curves annotated with the olive stage description at harvest enable to harvest drupes at a convenient stage depending on their use (table green or black fruits, oil fruit turning) for the best oil yield. However, the oil yield in the mill will depend on other technical parameters and may be more or less correlated to the oil content and thus the harvest date may be delayed for one or two months to enable water losses from fruits. This kind of resolution need to be restricted within a strategy of low-quality olive oil production.

Oil accumulation in the olive drupe begins by the second to third weeks of July, and is continuous until the end of October. Depending on the reference system (constant fresh-weight or dry-weight), variations are observed in the oil\% due to water fluxes (drought, rain) or maturation stages. Results on oil accumulation suggest that the potential yield is determined by the initial slope of the curves, these are different for the four cultivars. The potential oil yield is determined at the intersection of the oil accumulation rate straight line at the end of oil deposit (figure 3). Sclerification, other nutritional conditions and environmental stress trend to decrease the potential yield. However, these ways to affect yields are different, the former reduces the yield by the way of an accumulation of non-fatty dry matter, the latter decreases the accumulation of fats. for an agronomic use of this work, dealing with the mean weight of fat matter per fruit the optimum stages are 124 to 135 DAFB depending on the cultivar (figure 6). Rainfall and watering restore the yield. Thus it is important to determine the potential yield for cultivars. Furthermore, the relation between the potential yield and the mill yield could be addressed.

Thus, we plan cDNA libraries construction on developing fruits (7-15 DAFB) because differences were observed at these stages but they were not quantified to depletion of fruits for the remaining harvests. According to the model we can predict that the key stages to look for differences in gene expression between the four cultivars are the shift between cell division to cell expansion (50-60 DAFB), the period for sclerification of the pit (70-80 DAFB) and the period for maximum oil deposit (150-160 DAP). The construction of cDNA libraries at these stages are planned at the next season.

Acknowledgements. We thank André Vézhinet, Président du Conseil Général de l'Hérault, for enabling us to access to the olive trees. Thanks to all the staff of the rainfed orchard that maintain trees in perfect state. Data were partly gathered by Arthur de Cabissole during his stage ESA Angers July-September 2007. We thank the Association Bioclimatologique de I'Hérault in Fabrègues for providing climate data. We thank anonymous reviewers for their valuable suggestions. Conflict of interest: the authors have declared no conflict of interest.

\section{REFERENCES}

1. Lagravère $T$, Champolivier L, Lacombe S, Kleiber D, Bervillé A, Daydé J. Effect of temperature variations on fatty acid composition of the oil in standard and high oleic sunflower hybrids. In: Proc XVth Int Sunflower Conf., 2000, Toulouse: Pl A73-78.
2. Lagravère $T$, Lacombe $S$, Kleiber $D$, et al. Comparison of Fatty Acid Metabolism of Two Oleic and One Conventional Sunflower Hybrids: A New Hypothesis. J Agron Crop Sci $2004 ; 190$ : 223-9.

3. Haralampidis K, Milioni D, Sanchez J, Baltrusch M, Heinz E, Hatzopoulos P. Temporal and transient expression of stearoyl-ACP carrier protein desaturase gene during olive fruit development. J Exp Bot 1998 ; 49 : 1661-9.

4. Thakur BS, Chadha TR. Comparitive studies on the fatty acid composition of olive (Olea europaea L.) oil from mesocarp and kernel. Gartenbauwissenschaft 1991; 56: S.33-37

5. Hannachi $\mathrm{H}$, Sommerlatte $\mathrm{H}$, Breton $\mathrm{C}$, et al. Oleaster (var sylvestris) and subsp. cuspidata are suitable genetic resources for improvement of the olive (Olea europaea subsp. europaea var europaea). Genet Res Crop Evol $2009 ; 56$ : 393-403.

6. Vinha AF, Ferreres F, Silva BM, Valentão P, Gonçalves A, Pereira JA. M Oliveira B, Seabra RM, Andrade PB. Phenolic profiles of Portuguese olive fruits (Olea europaea L.): Influences of cultivar and geographical origin. Food Chemistry $2005 ; 89: 561-8$.

7. Beltrán G, Del Río C, Sánchez S, Martínez L. Seasonal changes in olive fruit characteristics and oil accumulation during ripening process. / Sci Food Agr $2004 ; 84$ : 1783-90.

8. Giannoulia K, Banilas G, Hatzopoulos P. Oleosin gene expression in olive. J Plant Physiol $2007 ; 164$ : 104-7.

9. De Gregorio A, Dugo G, Arena N, Patumi M. Lipoxygenase Activities In Ripening Olive Fruit Tissue. J Food Biochem 2000 ; 24 : 417-26.

10. Rangel B, Platt KAW, Thomson W. Ultrastructural aspects of the cytoplasmic origin and accumulation of oil in olive fruit (Olea europaea). Physiol Plant $1997 ; 101$ : 109-14.

11. Stiti N, Triki S, Hartmann MA. Formation of triterpenoids throughout olea europaea fruit ontogeny. Lipids $2007 ; 42: 55$.

12. Barone E, Gullo G, Zappia R, Inglese P. Effect of crop load on fruit ripening and olive oil (Olea europaea L.) quality. J of Horticulture Sc $1994 ; 69$ : 67-73.

13. Motilva M], Romero MP, Alegre S, Girona J. Influence of regulated deficit irrigation strategies applied to olive trees (Arbequina cultivar) on oil yield and oil composition during the fruit ripening period. I Sci Food Agri 2000 ; $80:$ 2037-43.

14. Salas JJ, Sanchez J, Ramli US, Manaf AM, Williams M, Harwood JL. Biochemistry of lipid metabolism in olive and other oil fruits. Progress in Lipid Research $2000 ; 39: 151-80$.

15. Pinatel C, Petit C, Ollivier D, Artaud J. Les fiches variétales de l'olivier. AFIDOL, 2006, www.afidol.org.

16. Wodner M, Lavee S, Epstein E. Identification and seasonal changes of glucose, fructose and mannitol in relation to oil accumulation during fruit development in Olea europaea (L.). Scientia Hort Amsterdam 1988; 36 : 47-54.

17. Brescia MA, Pugliese T, Hardy E, Sacco A. Compositional and structural investigations of ripening of table olives, Bella della Daunia, by means of traditional and magnetic resonance imaging analyses. Food Chem 2007 ; $105: 400-4$.

18. Giovannoni JJ. Genetic regulation of fruit development and ripening. The Plant Cell $2004 ; 16$ : S170-80.

19. Seymour GB, Manning K, Poole M, King G). The genetics and epigenetics of fruit development and ripening. Current Opinion in Plant Biology $2008 ; 11$ : 58-63. 